\title{
Prone Position as a Care Practice of the Physical Therapists in Public Neonatal Intensive Care Units in Southern Brazil Prone Position in NICU Southern Brazil
}

Micheli Martinello ( $\square$ michelimartinello@yahoo.com.br)

Santa Catarina State University https://orcid.org/0000-0002-1517-1545

Cíntia Johnston

Universidade Federal de Sao Paulo

Fabíola Isabel Suano Souza

Universidade Federal de Sao Paulo

Maria Wany Louzada Strufaldi

Universidade Federal de Sao Paulo

Research article

Keywords: Body position, Early intervention, Musculoskeletal development, Physical Therapy, Prone position

Posted Date: December 31st, 2019

DOI: https://doi.org/10.21203/rs.2.17307/v2

License: (c) (1) This work is licensed under a Creative Commons Attribution 4.0 International License.

Read Full License 
The authors have withdrawn this preprint from Research Square 